\title{
Clinical aspects of heart failure in individuals with diabetes
}

\author{
Christa D. Bowes ${ }^{1} \cdot$ Lillian F. Lien ${ }^{1} \cdot$ Javed Butler ${ }^{2}$
}

Received: 13 December 2018 / Accepted: 21 May 2019 / Published online: 24 July 2019

(C) Springer-Verlag GmbH Germany, part of Springer Nature 2019

\begin{abstract}
Heart failure (HF) is an important comorbidity in individuals with diabetes. Most commonly, the condition is secondary to ischaemia and hypertension. Diabetic cardiomyopathy is becoming increasingly recognised as a cause of HF and blood glucose control plays a pivotal role in the prevention and treatment of HF. Since the US Food and Drug Administration regulatory guidance in 2008, new glucose-lowering agents are evaluated routinely by cardiovascular outcome trials. These trials offer a wealth of knowledge and allow better understanding of the risks and benefits of contemporary diabetes medications. In this review, we will focus on the risks of HF with emerging glucose-lowering therapies and the safety of these medications in patients with established HF. We will summarise the guidance that is available for the treatment algorithm of diabetes in those with HF and highlight future areas of research.
\end{abstract}

Keywords Diabetes $\cdot$ Heart failure $\cdot$ Medical management $\cdot$ Review

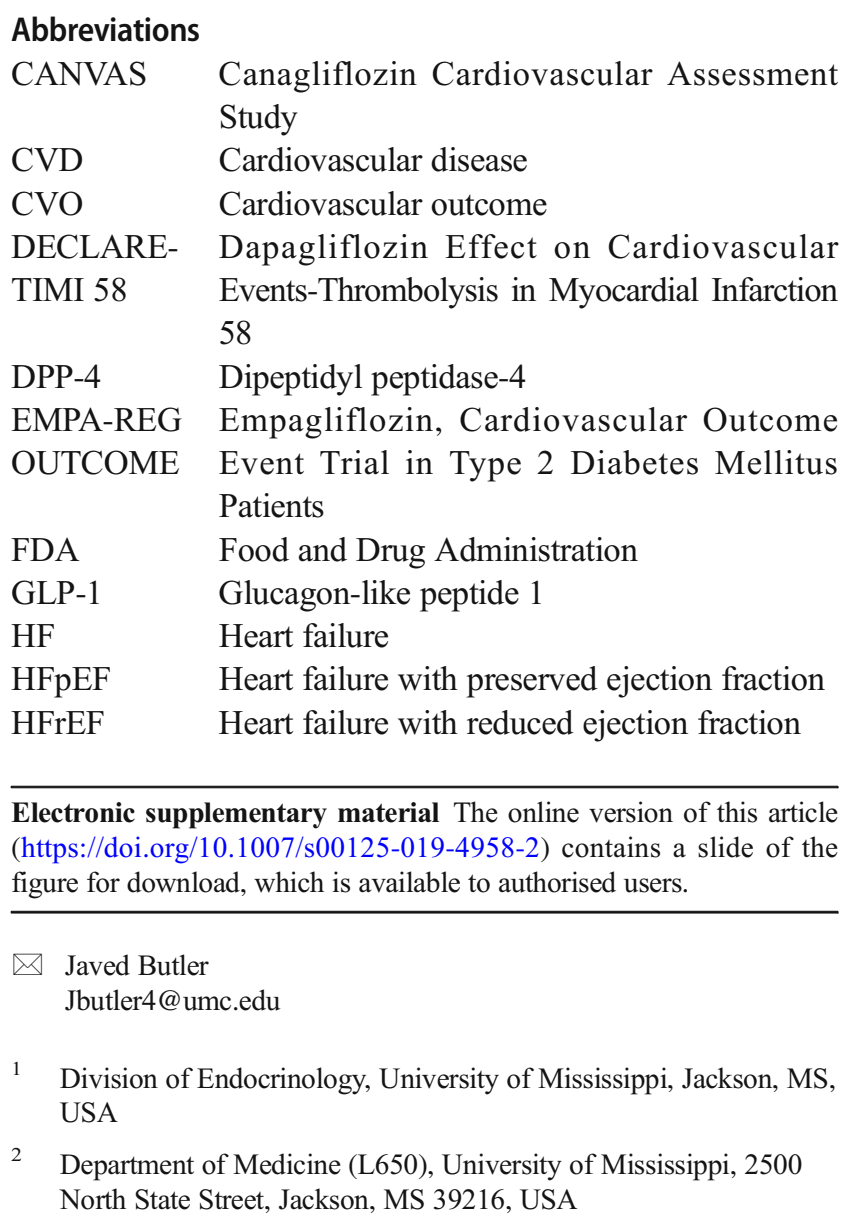
HHF Hospitalisation for heart failure
LEADER Liraglutide Effect and Action in Diabetes: Evaluation of Cardiovascular Outcome Results
MACE Major adverse cardiovascular events
MI Myocardial infarction
NT-proBNP N-terminal-pro-B-type-natriuretic peptide
NYHA New York Heart Association
REWIND Researching Cardiovascular Events with a Weekly Incretin in Diabetes
SAVOR- $\quad$ Saxagliptin Assessment of Vascular Outcomes
TIMI 53 Recorded in Patients with Diabetes Mellitus-
SGLT2 Sodium-glucose cotransporter 2
TECOS Trial Evaluating Cardiovascular Outcomes with Sitagliptin

\section{Introduction}

Diabetes is a predictor of morbidity and mortality in individuals with heart failure (HF) and is associated with worse prognosis. HF in individuals with diabetes is often secondary to ischaemic cardiomyopathy and hypertension. Furthermore, diabetic cardiomyopathy is becoming a recognised cause of $\mathrm{HF}$. Clinically, affected individuals initially have diastolic dysfunction, progressing to severe diastolic HF with preserved ejection fraction (HFpEF) and then to systolic dysfunction (HF with 


\section{CVO trials of glucose-lowering agents}

CANVAS Program Canagliflozin Cardiovascular Assessment Study (CANVAS) plus CANVAS-Renal (CANVAS-R)

CARMELINA Cardiovascular and Renal Microvascular Outcome study with Linagliptin

CAROLINA Cardiovascular Outcome trial of Linagliptin versus Glimepiride in Type 2 Diabetes

DECLARE-TIMI 58 Dapagliflozin Effect on Cardiovascular Events-Thrombolysis in Myocardial Infarction 58

ELIXA Evaluation of Lixisenatide in Acute Coronary Syndrome

EMPA-REG OUTCOME Empagliflozin, Cardiovascular Outcome Event Trial in Type 2 Diabetes Mellitus Patients

EXAMINE Examination of Cardiovascular Outcomes with Alogliptin versus Standard of Care

EXSCEL Exenatide Study of Cardiovascular Event Lowering

Harmony Outcomes A Long Term, Randomised, Double Blind, Placebo-Controlled Study to Determine the Effect of Albiglutide, When Added to Standard Blood Glucose Lowering Therapies, on Major Cardiovascular Events in Patients with Type 2 Diabetes Mellitus

LEADER Liraglutide Effect and Action in Diabetes: Evaluation of Cardiovascular Outcome Results

ORIGIN Outcome Reduction With Initial Glargine Intervention

PROactive PROspective Pioglitazone Clinical Trial in Macrovascular Events

RECORD Rosiglitazone Evaluated for Cardiovascular Outcomes in Oral Agent Combination Therapy for Type 2 Diabetes

REWIND Researching Cardiovascular Events with a Weekly Incretin in Diabetes

SAVOR-TIMI 53 Saxagliptin Assessment of Vascular Outcomes Recorded in Patients with Diabetes Mellitus-Thrombolysis in Myocardial Infarction 53

SUSTAIN-6 Trial to Evaluate Cardiovascular and Other Long-term Outcomes with Semaglutide in Subjects with Type 2 Diabetes

TECOS Trial Evaluating Cardiovascular Outcomes with Sitagliptin

VIVIDD Vildagliptin in Ventricular Dysfunction Diabetes

reduced ejection fraction [HFrEF]) [1]. Observational data suggest that hyperglycaemia is associated with HF development. Thus, such data may also suggest that improving glycaemic control plays an important role in prevention of diabetic cardiomyopathy $[2,3]$.

The rate of developing HF is two- to fivefold higher in diabetic vs non-diabetic individuals [4]. A heightened awareness of potential HF is needed when evaluating those at high risk. In a recent study using electronic medical records, individuals with diabetes of longer duration ( $>6$ years), advanced age, renal disease, poor glycaemic control, ischaemic heart disease, obesity and elevated diastolic blood pressure (BP) were identified as having highest risks for HF [5]. It has also been suggested that overall glycaemic burden, and not simply $\mathrm{HbA}_{1 \mathrm{c}}$ at the time of diagnosis, is a better predictor of HF risk [5]. Left ventricular diastolic dysfunction in asymptomatic, normotensive individuals with diabetes can be as prevalent as $75 \%$ [6]. Diabetes is associated with increased risk of cardiovascular death and hospitalisation for HF (HHF) in individuals with HFpEF and HFrEF [7]. Those with both HF and diabetes have more severe New York Heart Association (NYHA) class symptoms when compared with non-diabetic individuals with similar left ventricular ejection fraction [8].

The evolving medications and data for glucose-lowering agents can make the regimen decision increasingly complex. In this review, we describe the risks of HF with emerging glucose-lowering therapies, as well as safe use of medications in patients with established HF. We examine guidance available supporting the treatment algorithm for diabetes in individuals with $\mathrm{HF}$ and highlight future areas of research.

\section{The goal of glycaemic control in HF}

The reduction in microvascular disease (neuropathy, retinopathy and nephropathy) with improved glycaemic control is well established, but this therapeutic benefit is not as well established with macrovascular disease (coronary artery disease, peripheral vascular disease and stroke) [9]. The UK Prospective Diabetes Study (UKPDS) was a prospective 
observational study, demonstrating a $16 \%$ reduction in $\mathrm{HF}$ risk for every $1 \%$ decrease in $\mathrm{HbA}_{1 \mathrm{c}}$ [3]. Although improved control has been associated with lower HF risk, tight control $\left(\mathrm{HbA}_{1 \mathrm{c}}<7 \%\right.$ [53 mmol/mol] $)$ has been associated with higher mortality rate in individuals with moderate-to-severe HFrEF [10]. Thus, glycaemic control appears to have a U-shaped curve relative to mortality rate. A retrospective study of veterans with $\mathrm{HF}$ and diabetes demonstrated that the lowest mortality rate was with $\mathrm{HbA}_{1 \mathrm{c}}$ between $7.1 \%$ and $7.8 \%$ (54$62 \mathrm{mmol} / \mathrm{mol}$ ) [11].

\section{Medical management of diabetes: risk of developing $\mathrm{HF}$}

Prior to the 2008 US Food and Drug Administration (FDA)issued guidance for industry, 'Diabetes mellitus - evaluating cardiovascular risk in new antidiabetic therapies to treat type 2 diabetes', glucose-lowering agents were approved based solely on improvements in glycaemic control. The guidance aimed to establish that there would be no unacceptable increase in cardiovascular risk (specifically, ischaemic events) prior to the approval of new medications [12]. Now, with dedicated cardiovascular outcome (CVO) trials (see Table 1 for a summary of the results of these trials), clinicians may consider individual patient factors and individualise therapeutic regimens. Here, we discuss the risk of developing HF or increased risk of HHF for commonly used glucose-lowering agents.

\section{Medications with neutral effects on risk of HF}

Metformin Metformin is weight-neutral, does not increase the risk of hypoglycaemia and can also improve lipid profile. In addition, there is no suggested increase in risk of HF with use of this drug. The limited side-effects with use of this medication and its effectiveness in glucose-lowering has made it a first-line therapy, as outlined in the joint Consensus statement released by the American Association of Clinical Endocrinologists and American College of Endocrinology [13].

Sulfonylureas and insulin Use of insulin or sulfonylureas is associated with modest weight gain and hypoglycaemia. Initiating basal insulin in patients with diabetes has not demonstrated an increased risk of HF [14]. On the other hand, the safety data on sulfonylureas are based on observational studies, with conflicting results. There is a theoretical concern that increased insulin levels and weight gain might lead to an increased risk of HF. Compared with metformin, sulfonylureas may be associated with a higher mortality rate [15] and some studies suggest an increased risk for congestive HF $[16,17]$. This potentially unfavourable profile has led to sulfonylureas being placed towards the bottom of treatment algorithms [13]. The Cardiovascular Outcome trial of Linagliptin versus Glimepiride in Type 2 Diabetes (CAROLINA) trial is currently evaluating the cardiovascular impact of linagliptin (a dipeptidyl peptidase-4 [DPP-4] inhibitor) vs glimepiride (a sulfonylurea) in patients with diabetes who are at high cardiovascular risk (CinicalTrials.gov registration no. NCT01243424). Results from this study may provide important additional information on the cardiovascular safety of sulfonylureas.

Glucagon-like peptide 1 receptor agonists Glucagon-like peptide 1 (GLP-1) receptor agonists delay gastric emptying, reduce appetite, improve satiety and lead to weight loss. The Evaluation of Lixisenatide in Acute Coronary Syndrome (ELIXA) study was the first CVO trial for GLP-1 receptor agonists [18]. In this study, diabetic individuals who had a prior myocardial infarction (MI) or who were hospitalised for unstable angina within the previous 180 days (baseline HF rate, 22.4\%) were randomised to lixisenatide or placebo. There was no difference in the primary endpoint of major adverse cardiovascular events (MACE), which includes cardiovascular mortality, MI and stroke. In comparison, in a subsequent CVO trial in this class, Liraglutide Effect and Action in Diabetes: Evaluation of Cardiovascular Outcome Results (LEADER), individuals with high cardiovascular risk (baseline HF rate, $17.8 \%$ ) were randomised to liraglutide or placebo [18]. The primary endpoint of MACE occurred in significantly fewer participants in the liraglutide arm, primarily driven by a decrease in cardiovascular mortality. These findings directly led to expanded US FDA labelling for liraglutide, stating that it can be used for reducing MACE in adults with type 2 diabetes and established cardiovascular disease (CVD) [19].

Similar results were seen in the Trial to Evaluate Cardiovascular and Other Long-term Outcomes with Semaglutide in Subjects with Type 2 Diabetes (SUSTAIN-6) [20], in which participants with established CVD or at high risk for CVD (baseline HF rate, 23.6\%) were randomised to receive semaglutide or placebo; in this study, the primary endpoint of MACE was decreased in the treatment arm, primarily driven by a decrease in non-fatal stroke and MI. The Exenatide Study of Cardiovascular Event Lowering (EXSCEL) randomised diabetic individuals with increased cardiovascular risk (baseline HF rate, 16.2\%) to exenatide or placebo and found no difference in the primary endpoint of MACE [21]. These trials also demonstrated that lixisenatide [22], liraglutide [18], semaglutide [20] and exenatide [23] all had a neutral effect on HHF, which was a pre-specified secondary endpoint for each study.

CVO data for albiglutide was also recently published [24]. In diabetic individuals with CVD (baseline HF rate, 20\%) who were randomised to albiglutide or placebo, there was a significant reduction in the primary endpoint of MACE with 
Table 1 Findings from CVO trials

\begin{tabular}{|c|c|c|c|c|}
\hline Medication & Trial & Year & 3-Point MACE & HHF \\
\hline \multicolumn{5}{|l|}{ SGLT2 inhibitors } \\
\hline Empagliflozin & EMPA-REG OUTCOME [26] & 2015 & $\begin{array}{l}\text { Rate: } 37.4 \text { with empagliflozin vs } 43.9 \\
\text { with placebo per } 1000 \text { patient-years } \\
\text { (HR } 0.86 \text { [95\% CI } 0.74,0.99] \text { ) }\end{array}$ & $\begin{array}{l}\text { Rate: } 9.4 \text { with empagliflozin vs } 14.5 \\
\text { with placebo per } 1000 \text { patient-years } \\
\text { (HR } 0.65 \text { [ } 95 \% \text { CI } 0.50,0.85] \text { ) }\end{array}$ \\
\hline Canagliflozin & $\begin{array}{l}\text { CANVAS }[30,66] / \\
\text { CANVAS-R }[30,67]\end{array}$ & 2017 & $\begin{array}{l}\text { Rate: } 26.9 \text { with canagliflozin vs } 31.5 \\
\text { with placebo per } 1000 \text { patient-years } \\
\text { (HR } 0.86 \text { [95\% CI } 0.75,0.97] \text { ) }\end{array}$ & $\begin{array}{l}\text { Rate: } 5.5 \text { with canagliflozin vs } 9.0 \text { with } \\
\text { placebo per } 1000 \text { patient-years } \\
\text { (HR } 0.67 \text { [ } 95 \% \text { CI } 0.52,0.77] \text { ) }\end{array}$ \\
\hline Dapagliflozin & DECLARE-TIMI 58 [32] & 2018 & $\begin{array}{l}\text { Rate: } 22.6 \text { with dapagliflozin vs } 24.2 \\
\text { with placebo per } 1000 \text { patient-years } \\
\text { (HR } 0.93 \text { [95\% CI } 0.84,1.03] \text { ) }\end{array}$ & $\begin{array}{l}\text { Rate: } 6.2 \text { with dapagliflozin vs } 8.5 \text { with } \\
\text { placebo per } 1000 \text { patient-years } \\
\text { (HR } 0.73 \text { [95\% CI } 0.61,0.88] \text { ) }\end{array}$ \\
\hline \multicolumn{5}{|c|}{ GLP-1 receptor agonists } \\
\hline Lixisenatide & ELIXA [22] & 2015 & $\begin{array}{l}13.4 \% \text { with lixisenatide vs } 13.2 \% \text { with } \\
\text { placebo } \\
\text { (HR } 1.02 \text { [95\% CI } 0.89,1.17] \text { ) }\end{array}$ & $\begin{array}{l}4.0 \% \text { with lixisenatide vs } 4.2 \% \text { with } \\
\text { placebo } \\
\text { (HR } 0.96[95 \% \text { CI } 0.75,1.23] \text { ) }\end{array}$ \\
\hline Liraglutide & LEADER [18] & 2016 & $\begin{array}{l}13.0 \% \text { with liraglutide vs } 14.9 \% \text { with } \\
\text { placebo } \\
\text { (HR } 0.87 \text { [ } 95 \% \text { CI } 0.78,0.97] \text { ) }\end{array}$ & $\begin{array}{l}4.7 \% \text { with liraglutide vs } 5.3 \% \text { with } \\
\text { placebo } \\
\text { (HR } 0.87 \text { [95\% CI } 0.73,1.05] \text { ) }\end{array}$ \\
\hline Semaglutide & SUSTAIN-6 [20] & 2016 & $\begin{array}{l}6.6 \% \text { with semaglutide vs } 8.9 \% \text { with } \\
\text { placebo } \\
\text { (HR } 0.74[95 \% \text { CI } 0.58,0.95] \text { ) }\end{array}$ & $\begin{array}{l}3.6 \% \text { with semaglutide vs } 3.3 \% \text { with } \\
\text { placebo } \\
\text { (HR } 1.11[95 \% \text { CI } 0.77,1.61])\end{array}$ \\
\hline Exenatide & EXSCEL [23] & 2017 & $\begin{array}{l}11.4 \% \text { with exenatide vs } 12.2 \% \text { with } \\
\text { placebo } \\
\text { (HR } 0.91[95 \% \text { CI } 0.83,1.00] \text { ) }\end{array}$ & $\begin{array}{l}3 \% \text { with exenatide vs } 3.1 \% \text { with } \\
\text { placebo } \\
\text { (HR } 0.94[95 \% \text { CI } 0.78,1.13] \text { ) }\end{array}$ \\
\hline Albiglutide & Harmony Outcomes [24] & 2018 & $\begin{array}{l}7 \% \text { with albiglutide vs } 9 \% \text { with placebo } \\
\text { (HR } 0.78[95 \% \text { CI } 0.68,0.90] \text { ) }\end{array}$ & $\begin{array}{l}4 \% \text { with albiglutide vs } 5 \% \text { with } \\
\text { placebo }^{\mathrm{a}} \\
\text { (HR } 0.85[95 \% \text { CI } 0.70,1.04])\end{array}$ \\
\hline \multicolumn{5}{|l|}{ DPP-4 inhibitors } \\
\hline Saxagliptin & SAVOR-TIMI 53 [38] & 2013 & $\begin{array}{l}7.3 \% \text { with saxagliptin vs } 7.2 \% \text { with } \\
\text { placebo } \\
\text { (HR } 1.00[95 \% \text { CI } 0.89,1.12] \text { ) }\end{array}$ & $\begin{array}{l}3.5 \% \text { with saxagliptin vs } 2.8 \% \text { with } \\
\text { placebo } \\
\text { (HR } 1.27[95 \% \text { CI } 1.07,1.51])\end{array}$ \\
\hline Alogliptin & EXAMINE [53] & 2013 & $\begin{array}{l}11.3 \% \text { with alogliptin vs } 11.8 \% \text { with } \\
\text { placebo } \\
\text { (HR } 0.96 \text {; upper limit of } 95 \% \mathrm{CI} \leq 1.16 \text { ) }\end{array}$ & $\begin{array}{l}3.1 \% \text { with alogliptin vs } 2.9 \% \text { with } \\
\text { placebo } \\
\text { (HR } 1.07[95 \% \text { CI } 0.79,1.46])\end{array}$ \\
\hline Sitagliptin & TECOS [41] & 2015 & $\begin{array}{l}11.4 \% \text { with sitagliptin vs } 11.6 \% \text { with } \\
\text { placebo } \\
\text { (HR } 0.99[95 \% \text { CI } 0.89,1.08] \text { ) }\end{array}$ & $\begin{array}{l}3.1 \% \text { with sitagliptin vs } 3.1 \% \text { with } \\
\text { placebo } \\
\text { (HR } 1.00[95 \% \text { CI } 0.83,1.20])\end{array}$ \\
\hline Linagliptin & CARMELINA [44] & 2018 & $\begin{array}{l}12.4 \% \text { with linagliptin vs } 12.1 \% \text { with } \\
\text { placebo } \\
\text { (HR } 1.02[95 \% \text { CI } 0.98,1.17])\end{array}$ & $\begin{array}{l}6.0 \% \text { with linagliptin vs } 6.5 \% \text { with } \\
\text { placebo } \\
\text { (HR } 0.90[95 \% \text { CI } 0.74,1.08] \text { ) }\end{array}$ \\
\hline
\end{tabular}

${ }^{a}$ Data are for composite of death from cardiovascular causes or HHF

CANVAS-R, CANVAS-Renal; CARMELINA, Cardiovascular and Renal Microvascular Outcome Study with Linagliptin; ELIXA, Evaluation of Lixisenatide in Acute Coronary Syndrome; EXAMINE, Examination of Cardiovascular Outcomes with Alogliptin versus Standard of Care; EXSCEL, Exenatide Study of Cardiovascular Event Lowering; SUSTAIN-6, Trial to Evaluate Cardiovascular and Other Long-term Outcomes with Semaglutide in Subjects with Type 2 Diabetes

albiglutide, driven by a reduction in MI. Similar to other trials of drugs in this class, a neutral effect on the secondary composite endpoint of death from cardiovascular causes and HHF was demonstrated.

Recently, the Researching Cardiovascular Events with a Weekly Incretin in Diabetes (REWIND) trial on dulaglutide was published. REWIND evaluated a limited number of participants with established CVD at baseline. Results demonstrate a reduction in MACE in those treated with dulaglutide.
Thus, data continue to support significant cardiovascular benefit with this medication class [25].

\section{Medications that may reduce risk of developing HF}

Sodium-glucose cotransporter 2 inhibitors Sodium-glucose cotransporter 2 (SGLT2) inhibitors are associated with weight loss and both systolic and diastolic BP reduction. Empagliflozin was first-in-class to have published CVO data; 
the Empagliflozin, Cardiovascular Outcome Event Trial in Type 2 Diabetes Mellitus Patients (EMPA-REG OUTCOME) study [26] included participants with established CVD (baseline HF rate, $10.1 \%$ ) who were randomised to empagliflozin or placebo. There was a significant decrease in the primary endpoint of MACE with empagliflozin use, driven by a decrease in cardiovascular death. This led to approval of an indication for empagliflozin by the US FDA in 2016, to reduce the risk of cardiovascular death in adults with type 2 diabetes and CVD [27]. Although not a primary endpoint in EMPA-REG OUTCOME, a significant decrease in the rate of HHF was also seen in the empagliflozin arm. Findings were consistent across subgroups, regardless of dose, age, race and eGFR [28].

Similarly, in the Canagliflozin Cardiovascular Assessment Study (CANVAS) Program, canagliflozin reduced rates of $\mathrm{HHF}$ in participants at high cardiovascular risk (baseline HF rate, $14.4 \%$ ), although a reduction in cardiovascular mortality was not demonstrated $[29,30]$. The association between SGLT2 inhibitors and improved rates of HHF is further supported by a multinational study with data from real-world practice [31] and the recently published Dapagliflozin Effect on Cardiovascular Events-Thrombolysis in Myocardial Infarction 58 (DECLARE-TIMI 58) study [32]. DECLARETIMI 58 included diabetic participants at high cardiovascular risk (baseline HF rate, 10\%), but differed from previous studies by involving a larger population without known atherosclerotic CVD [32]. Although dapagliflozin was non-inferior vs placebo in its effects on MACE, the results did support improved HHF rates.

Indeed, although specific trials have differed in detail, overall effects have been largely consistent and suggest a class effect on HHF rate [32]. There are multiple proposed mechanisms to explain the benefit of SGLT2 inhibitors on HF. Benefits were seen early on in the EMPA-REG Outcome study, suggesting this effect may actually be independent of glycaemic control. A suggested mechanism involves the role of SGLT2-mediated glucose uptake and its interaction with the $\mathrm{Na}^{+}-\mathrm{H}^{+}$exchanger; this exchanger is responsible for the majority of sodium reuptake in the kidney, which is increased in HF and may play a role in diuretic resistance [33, 34]. Other proposed mechanisms include decreased plasma volume, increased natriuresis, weight loss and improved haemodynamics.

\section{Medications that may increase risk of developing HF}

Thiazolidinediones Thiazolidinediones increase insulin sensitivity in peripheral tissues but are associated with fluid retention, subcutaneous fat accumulation and increased bone fractures. In the PROspective Pioglitazone Clinical Trial In Macrovascular Events (PROactive), despite excluding individuals with NYHA class II HF or above, pioglitazone demonstrated increased rates of HHF compared with placebo [35]. The Rosiglitazone Evaluated for Cardiovascular Outcomes in Oral Agent Combination Therapy for Type 2 Diabetes (RECORD) trial demonstrated comparable results, with an increased rate of HHF with rosiglitazone [36]. Therefore, thiazolidinediones can only be recommended for use with significant caution in those at risk of developing HF.

DPP-4 inhibitors DPP-4 inhibitors result in increased fasting and postprandial GLP-1 levels and are better tolerated than GLP-1 receptor agonists (less nausea) but lack the benefit of weight loss. The Saxagliptin Assessment of Vascular Outcomes Recorded in Patients with Diabetes MellitusThrombolysis in Myocardial Infarction 53 (SAVOR-TIMI 53), evaluating participants with diabetes and established or high risk for CVD (12.8\% with prior history of HF), had unexpected results $[37,38]$; although there was no difference in the primary endpoint of MACE, surprisingly, increased rates of HHF were demonstrated. This was most notable in those with a previous history of $\mathrm{HF}$, eGFR $<60 \mathrm{ml} \mathrm{min}^{-1}$ $(1.73 \mathrm{~m})^{-2}$ and elevated N-terminal-pro-B-type-natriuretic peptide (NT-proBNP) at baseline. Similarly, in the Examination of Cardiovascular Outcomes with Alogliptin versus Standard of Care (EXAMINE) study, in which individuals with diabetes and acute coronary syndrome in the previous $15-90$ days ( $27.9 \%$ with prior HF) were randomised to alogliptin or placebo [39], there was no difference in the primary endpoint of MACE but alogliptin increased the rate of HHF although this increase was not statistically significant. Those with increased HHF were older, with longer duration of diabetes, and had reduced eGFR $\left(\sim 55 \mathrm{ml} \mathrm{min}^{-1}[1.73 \mathrm{~m}]^{-2}\right)$, previous coronary artery bypass, peripheral vascular disease and a personal history of HF [40]. In contrast, the Trial Evaluating Cardiovascular Outcomes with Sitagliptin (TECOS) enrolled individuals with type 2 diabetes and established CVD (HF rate, 18.3\%) [41] and the results were neutral for the primary endpoint of cardiovascular death, nonfatal MI, non-fatal stroke or hospitalisation for unstable angina, and also for the secondary endpoint of HHF. In addition, some post-marketing studies have suggested no increased risk of congestive $\mathrm{HF}$ among patients with diabetes using incretinbased therapies [42, 43].

In 2017, the FDA placed an HF warning on all agents in this class. Nonetheless, it could be suggested that this has not been truly established, especially when considering the most recent data published for linagliptin in the Cardiovascular and Renal Microvascular Outcome Study with Linagliptin (CARMELINA), demonstrating no increased risk of HHF in a population at particularly high risk of $\mathrm{HF}$ (with coronary artery disease [CAD] or chronic kidney disease $[\mathrm{CKD}]$ ), with $26.8 \%$ of the patients having known HF [44]. 


\section{Medical management of diabetes: implications for individuals with HF}

\section{Medications with neutral effects in individuals with HF}

Metformin Metformin is now considered safe to use in certain patients with $\mathrm{HF}$ and may be associated with improved clinical outcomes $[45,46]$. So far there has been no RCTs evaluating metformin's use in HF, so these conclusions are based on observational data. Initial reports of lactic acidosis with other biguanides led to similar concerns about metformin. Previously, the US FDA had placed an absolute contraindication against its use in HF, which was later removed (2006), although caution on use in acute and advanced HF remains [47].

Guidance specifically for the treatment of type 2 diabetes in those with $\mathrm{HF}$ continues to recommend metformin as first-line therapy [48, 49]. The 2018 update to the American Diabetes Association (ADA) and European Association for the Study of Diabetes (EASD) 2015 publication, 'Management of Hyperglycemia in Type 2 Diabetes' [50], advises the initial assessment of cardiovascular status and offers a separate algorithm for metformin treatment of type 2 diabetic individuals with HF. Metformin remains a first-line therapy as long as moderate renal function is maintained (eGFR $>30 \mathrm{ml} \mathrm{min}^{-1}$ $[1.73 \mathrm{~m}]^{-2}$ ) [50].

GLP-1 receptor agonists Although GLP-1 receptor agonists have not been associated with an increased rate of HHF in diabetes in the large clinical trials published so far, concern has been raised in smaller studies with different patient populations, specifically in those with HF. In an evaluation of individuals with $\mathrm{HFrEF}$ after recent hospitalisation, liraglutide demonstrated a neutral effect on time-to-death, time-to-rehospitalisation for HF and NT-proBNP levels [51]. When further evaluated in individuals with stable HFrEF, liraglutide significantly increased heart rate ( 7 beats $/ \mathrm{min})$ compared with placebo and increased rates of serious cardiac events (ventricular tachycardia, atrial fibrillation, acute coronary syndrome and worsening of congestive HF) [52]. These later results raise concern regarding the net benefit of liraglutide in HFrEF patients. Currently, data are lacking to determine whether this is a class effect. The unique US FDA indication for liraglutide acknowledges that there is clear benefit for individuals with established CVD but further research needs to evaluate safety in those with HFrEF. GLP-1 receptor agonists remain recommended as a second-line therapy in those with known CVD, and in those with HF if an SGLT2 inhibitor is not appropriate [50].

\section{Medications that may reduce risk of developing HF}

SGLT2 inhibitors SGLT2 inhibitors have shown a significant reduction in HHF, but these findings come from studies that were not designed to evaluate benefits in people with HF. EMPA-REG OUTCOME and the CANVAS Program only included a small population of participants with $\mathrm{HF}$ at baseline (10\% and $14 \%$, respectively) $[26,29,30]$. Sub-analyses of those with HF in EMPA-REG OUTCOME continued to show a benefit of decreased HHF with empagliflozin [28]. In 2018, the ADA/EASD recommended SGLT2 inhibitors as secondline therapy for diabetes in individuals with HF, with preference given to empagliflozin based on the CVD benefits shown in EMPA-REG OUTCOME, as long as the patient has adequate renal function (eGFR $>45 \mathrm{ml} \mathrm{min}^{-1}[1.73 \mathrm{~m}]^{-2}$ ) [50].

Given the potentially increased use of SGLT2 inhibitors in HF patients, this class of drugs must be further studied in this population. Currently, large RCTs of SGLT2 inhibitors are enrolling participants with HF, although diabetes is not a mandatory inclusion criterion. Two of these will evaluate empagliflozin vs placebo, with the primary endpoints of cardiovascular death and HHF, in individuals with either HFrEF (Empagliflozin Outcome Trial in Patients with Chronic Heart Failure with Reduced Ejection Fraction [EMPERORReduced]; ClinicalTrials.gov registration no. NCT03057977) or HFpEF (Empagliflozin Outcome Trial in Patients with Chronic Heart Failure with Preserved Ejection Fraction [EMPEROR-Preserved]; ClinicalTrials.gov registration no. NCT03057951). A third study will assess dapagliflozin vs placebo in individuals with HFrEF, with the primary endpoints of cardiovascular death and HHF (Study to Evaluate the Effect of Dapagliflozin on the Incidence of Worsening Heart Failure or Cardiovascular Death in Patients With Chronic Heart Failure [DAPA-HF]; ClinicalTrials.gov registration no. NCT03036124).

\section{Medications that may increase risk of developing HF}

DPP-4 inhibitors DPP-4 inhibitors have become popular as they can be taken orally and are better tolerated than GLP-1 agents. Concerns of worsening HF with this class were based on trials in individuals with stable diabetes but limited numbers had established HF [38, 41, 44, 53]. Publicly available data in the US FDA Adverse Event Reporting System was reviewed with the aim of evaluating the association between HF and DPP-4 inhibitors [54]. An increased association with saxagliptin was found with this class of drugs, as previously suggested in SAVOR-TIMI 53. Interestingly, there was an increase in HF with sitagliptin, which conflicts with the TECOS findings [41].

There are currently no specific guidelines on how to manage patients at high risk for HF who are already being treated with DPP-4 inhibitors. Published CVO trials may underestimate the risk of DPP-4 inhibitors in established HF, although this has been poorly studied. The Vildagliptin in Ventricular Dysfunction Diabetes (VIVIDD) study was designed to evaluate the effects of DPP-4 inhibitors in individuals with left 
ventricular dysfunction [55]. Increased left ventricular volumes were demonstrated with DPP-4 inhibitor use, although the clinical significance of this finding is unknown. Until further studies evaluate use of DPP-4 inhibitors in this designated population, clinicians need to be cautious in prescribing these drugs to patients at high risk for HF and should consider avoiding their use in those with known HF.

Thiazolidinediones, sulfonylureas and insulin There have been no RCTs evaluating the effects of thiazolidinediones, sulfonylureas or insulin in diabetic individuals with HF. Thiazolidinediones are contraindicated in NYHA class IIIIV HF and should be used with caution in those at risk for HF. Sulfonylureas and insulin are often considered third-line therapies for type 2 diabetes. Sulfonylureas have an unclear safety profile in HF. Individuals with HFrEF who are taking insulin have a significantly worse prognosis than those not on insulin [56], although it is not known whether this is a marker of advanced disease state or a causal relationship.

\section{Pharmacological management of HF in diabetic individuals}

No specific restrictions exist on the use of medications for treating $\mathrm{HF}$ in diabetic individuals. Angiotensin converting enzyme (ACE) inhibitors have demonstrated mortality benefit in type 2 diabetes [57]. There are less data on angiotensin receptor blockers (ARBs) specifically in diabetic individuals, but these have been proven to delay the first HHF in diabetes [58]. Expert opinion recommends starting at low doses of ARBs and titrating upwards, with frequent monitoring of electrolytes and renal function, given risks such as hyperkalaemia [59].

Concern has been expressed regarding blunting of hypoglycaemic symptoms with use of $\beta$-blockers. Nonetheless, their mortality benefit in diabetes is clear and, therefore, this class is recommended [57]. In addition, carvedilol may have a favourable effect on insulin resistance; however, metoprolol has been shown to increase $\mathrm{HbA}_{1 \mathrm{c}}$ [60]. So far, there is no specific guidance regarding which $\beta$-blocker to use in a hierarchical fashion.

Both spironolactone and eplerenone have been shown to significantly decrease morbidity and mortality in individuals with HFrEF [61, 62]. Data on the impact of mineralocorticoid receptor blockade on glycaemic control are conflicting, but their safety is largely accepted in diabetic patients with HF [63]. Given risk of hyperkalaemia with these drugs, clinicians should monitor renal function and electrolytes.

Sacubitril/valsartan (LCZ696) has demonstrated superiority to enalapril in reducing the risk of death and HHF [64] and has been shown to improve glycaemic control; participants in the Prospective Comparison of ARNI with ACEI to
Determine Impact on Global Mortality and Morbidity in Heart Failure (PARADIGM-HF) trial who received sacubitril/valsartan displayed a greater reduction in $\mathrm{HbA}_{1 \mathrm{c}}$ [65].

\section{Conclusion}

Therapies for diabetes were initially approved only on the basis of blood glucose control. Now, through CVO trials, we have knowledge on novel therapies and a better understanding of how to individualise treatment in populations at high risk for HF (see Fig. 1 for a summary of HF outcomes with select glucose-lowering therapies). Metformin remains the first-line therapy in individuals with diabetes with and without HF, with second-line options including SGLT2 inhibitors. GLP-1 receptor agonists provide another second-line option but require further focused HF trials to establish safety. Caution must be

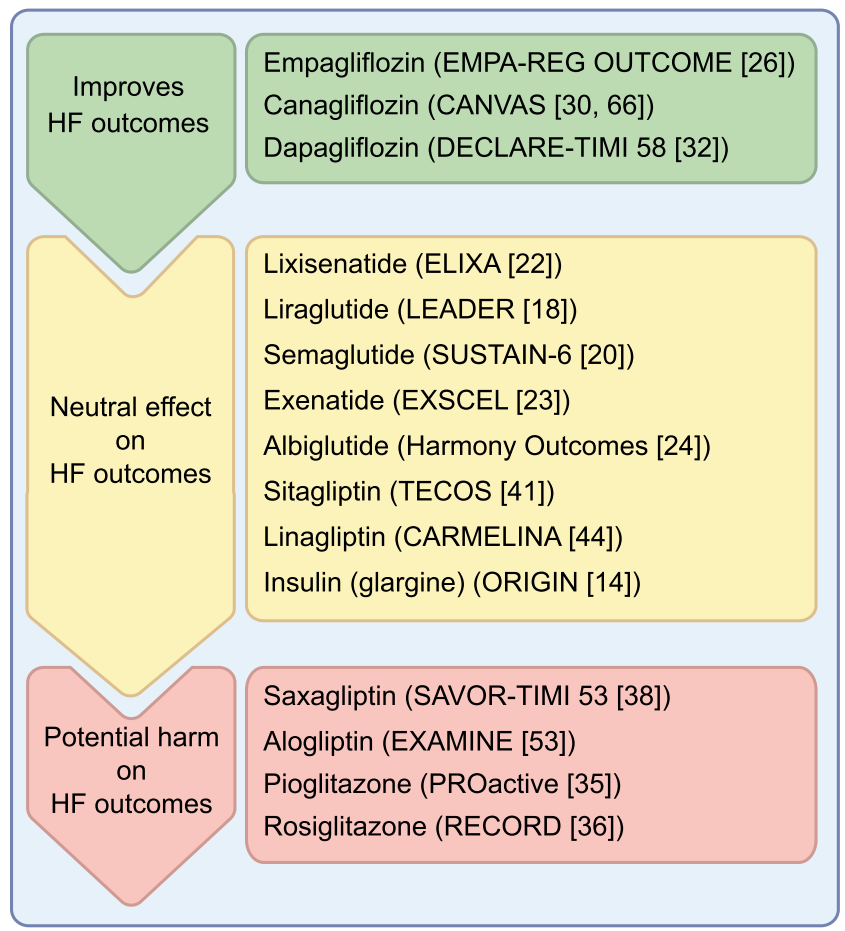

Fig. $1 \mathrm{HF}$ outcomes with select glucose-lowering therapies. Note that although sitagliptin was found in CVO trials to have a neutral effect on heart failure, a later review of adverse event reporting data indicated that it may increase heart failure. CARMELINA, Cardiovascular and Renal Microvascular Outcome Study with Linagliptin; ELIXA, Evaluation of Lixisenatide in Acute Coronary Syndrome; EXAMINE, Examination of Cardiovascular Outcomes with Alogliptin versus Standard of Care; EXSCEL, Exenatide Study of Cardiovascular Event Lowering; ORIGIN, Outcome Reduction With Initial Glargine Intervention; PROactive, PROspective Pioglitazone Clinical Trial In Macrovascular Events; RECORD, Rosiglitazone Evaluated for Cardiovascular Outcomes in Oral Agent Combination Therapy for Type 2 Diabetes; SUSTAIN-6, Trial to Evaluate Cardiovascular and Other Long-term Outcomes with Semaglutide in Subjects with Type 2 Diabetes. This figure is available as a downloadable slide 
used with DPP-4 inhibitors in those at risk for HF due to an increased risk of $\mathrm{HF}$ outcomes with some drugs in this class, although whether this is a class effect is still debated. Meanwhile, thiazolidinediones remain contraindicated in those with NYHA class III-IV HF. Further studies will add to the complexity of treatment algorithms for diabetic patients with HF. More robust population studies of HF subgroups are needed in well-designed clinical trials for further treatment stratification. New data will support development of more individualised guidelines for management of diabetic individuals at risk for, or already with, HF and will permit evidencebased decisions when devising treatment regimens for these patients.

Duality of interest LFL has served as a consultant for Tandem, Novo Nordisk, Merck, Eli Lilly and Sanofi and receives royalties from Springer Inc. JB has received research support from the National Institutes of Health, Patient Centered Outcomes Research Institute and the European Union and serves as a consultant for Adrenomed, Amgen, Array, AstraZeneca, Bayer, Berlin Cures, Boehringer Ingelheim, Bristol Myers Squib, CVRx, G3 Pharmaceutical, Janssen, Lantheus, Luitpold, Medtronic, Merck, Novartis, Relypsa, Roche, Sanofi, StealthPeptide, SC Pharma, Vifor and ZS Pharma. CDB reports no duality of interest associated with this manuscript.

Contribution statement All authors were responsible for drafting the article and revising it critically for important intellectual content. All authors approved the version to be published.

\section{References}

1. Jia G, Whaley-Connell A, Sowers JR (2018) Diabetic cardiomyopathy: a hyperglycaemia- and insulin-resistance-induced heart disease. Diabetologia 61(1):21-28. https://doi.org/10.1007/s00125017-4390-4

2. Iribarren C, Karter AJ, Go AS et al (2001) Glycemic control and heart failure among adult patients with diabetes. Circulation 103(22):2668-2673. https://doi.org/10.1161/01.CIR.103.22.2668

3. Stratton IM, Adler AI, Neil HA et al (2000) Association of glycaemia with macrovascular and microvascular complications of type 2 diabetes (UKPDS 35): prospective observational study. BMJ 321(7258):405-412. https://doi.org/10.1136/bmj.321.7258. 405

4. Kannel WB, Hjortland M, Castelli WP (1974) Role of diabetes in congestive heart failure: the Framingham study. Am J Cardiol 34(1):29-34. https://doi.org/10.1016/0002-9149(74)90089-7

5. Nichols GA, Gullion CM, Koro CE, Ephross SA, Brown JB (2004) The incidence of congestive heart failure in type 2 diabetes: an update. Diabetes Care 27(8):1879-1884. https://doi.org/10.2337/ diacare.27.8.1879

6. Boyer JK, Thanigaraj S, Schechtman KB, Perez JE (2004) Prevalence of ventricular diastolic dysfunction in asymptomatic, normotensive patients with diabetes mellitus. Am J Cardiol 93(7): 870-875. https://doi.org/10.1016/j.amjcard.2003.12.026

7. MacDonald MR, Petrie MC, Varyani F et al (2008) Impact of diabetes on outcomes in patients with low and preserved ejection fraction heart failure: an analysis of the candesartan in heart failure: assessment of reduction in mortality and morbidity (CHARM) programme. Eur Heart J 29(11):1377-1385. https://doi.org/10.1093/ eurheartj/ehn153
8. Suskin N, McKelvie RS, Burns RJ et al (2000) Glucose and insulin abnormalities relate to functional capacity in patients with congestive heart failure. Eur Heart J 21(16):1368-1375. https://doi.org/10. 1053/euhj.1999.2043

9. Ray KK, Seshasai SR, Wijesuriya S et al (2009) Effect of intensive control of glucose on cardiovascular outcomes and death in patients with diabetes mellitus: a meta-analysis of randomised controlled trials. Lancet 373(9677):1765-1772. https://doi.org/10.1016/ S0140-6736(09)60697-8

10. Eshaghian S, Horwich TB, Fonarow GC (2006) An unexpected inverse relationship between $\mathrm{HbA1} \mathrm{c}$ levels and mortality in patients with diabetes and advanced systolic heart failure. Am Heart J 151: 91

11. Aguilar D, Bozkurt B, Ramasubbu K, Deswal A (2009) Relationship of hemoglobin A1C and mortality in heart failure patients with diabetes. J Am Coll Cardiol 54(5):422-428. https:// doi.org/10.1016/j.jacc.2009.04.049

12. US Food \& Drug Administration (2018) Guidance for industry: diabetes mellitus - evaluating cardiovascular risk in new antidiabetic therapies to treat type 2 diabetes. Available from www.fda. gov/downloads/Drugs/Guidances/ucm071627.pdf. Accessed 5 Jan 2019

13. Garber AJ, Abrahamson MJ, Barzilay JI et al (2018) Consensus statement by the American Association of Clinical Endocrinologists and American College of Endocrinology on the comprehensive type 2 diabetes management algorithm - 2018 executive summary. Endocr Pract 24(1):91-120. https://doi.org/10. 4158/CS-2017-0153

14. Gerstein HC, Bosch J, Dagenais GR et al (2012) Basal insulin and cardiovascular and other outcomes in dysglycemia. N Engl J Med 367(4):319-328. https://doi.org/10.1056/NEJMoa1203858

15. MacDonald MR, Eurich DT, Majumdar SR et al (2010) Treatment of type 2 diabetes and outcomes in patients with heart failure: a nested case-control study from the U.K. General Practice Research Database. Diabetes Care 33(6):1213-1218. https://doi. org/10.2337/dc09-2227

16. Tzoulaki I, Molokhia M, Curcin Vet al (2009) Risk of CVD and all cause mortality among patients with type 2 diabetes prescribed oral antidiabetes drugs: retrospective cohort study using UK general practice research database. BMJ 339(dec03 1):b4731. https://doi. org $/ 10.1136 / \mathrm{bmj} . \mathrm{b} 4731$

17. Roumie CL, Min JY, D Agostino McGowan L et al (2017) Comparative safety of sulfonylurea and metformin monotherapy on the risk of heart failure: a cohort study. J Am Heart Assoc 6: e005379

18. Marso SP, Daniels GH, Brown-Frandsen K et al (2016) Liraglutide and cardiovascular outcomes in type 2 diabetes. N Engl J Med 375(4):311-322. https://doi.org/10.1056/NEJMoa1603827

19. Novo Nordisk (2017) Victoza ${ }^{\circledR}$ approved in the US as the only type 2 diabetes treatment indicated to reduce the risk of major adverse cardiovascular events. Available from www.novonordisk.com/ content/Denmark/HQ/www-novonordisk-com/en_gb/home/media/ news-details.1255872.html. Accessed 5 Jan 2019

20. Marso SP, Bain SC, Consoli A et al (2016) Semaglutide and cardiovascular outcomes in patients with type 2 diabetes. $\mathrm{N}$ Engl J Med 375(19):1834-1844. https://doi.org/10.1056/NEJMoa1607141

21. Mentz RJ, Bethel MA, Gustavson S et al (2017) Baseline characteristics of patients enrolled in the Exenatide study of cardiovascular event lowering (EXSCEL). Am Heart J 187:1-9. https://doi.org/10. 1016/j.ahj.2017.02.005

22. Pfeffer MA, Claggett B, Diaz R et al (2015) Lixisenatide in patients with type 2 diabetes and acute coronary syndrome. N Engl J Med 373(23):2247-2257. https://doi.org/10.1056/NEJMoa1509225

23. Holman RR, Bethel MA, Mentz RJ et al (2017) Effects of onceweekly exenatide on cardiovascular outcomes in type 2 diabetes. $\mathrm{N}$ 
Eng1 J Med 377(13):1228-1239. https://doi.org/10.1056/ NEJMoa1612917

24. Hernandez AF, Green JB, Janmohamed S et al (2018) Albiglutide and cardiovascular outcomes in patients with type 2 diabetes and CVD (harmony outcomes): a double-blind, randomised placebocontrolled trial. Lancet 392(10157):1519-1529. https://doi.org/10. 1016/S0140-6736(18)32261-X

25. Gerstein HC, Colhoun HM, Dagenais GR et al (2019) Dulaglutide and cardiovascular outcomes in type 2 diabetes (REWIND): a double-blind, randomised placebo-controlled trial. Lancet. https://doi. org/10.1016/S0140-6736(19)31149-3

26. Zinman B, Wanner C, Lachin JM et al (2015) Empagliflozin, cardiovascular outcomes, and mortality in type 2 diabetes. $\mathrm{N}$ Engl $\mathrm{J}$ Med 373(22):2117-2128. https://doi.org/10.1056/NEJMoa1504720

27. US Food \& Drug Administration (2016) FDA approves Jardiance to reduce cardiovascular death in adults with type 2 diabetes. Available from www.fda.gov/newsevents/newsroom/ pressannouncements/ucm531517.htm. Accessed 5 Jan 2019

28. Fitchett D, Zinman B, Wanner C et al (2016) Heart failure outcomes with empagliflozin in patients with type 2 diabetes at high cardiovascular risk: results of the EMPA-REG OUTCOME trial. Eur Heart J 37(19):1526-1534. https://doi.org/10.1093/eurheartj/ ehv728

29. Mahaffey KW, Neal B, Perkovic V et al (2018) Canagliflozin for primary and secondary prevention of cardiovascular events: results from the CANVAS program (Canagliflozin Cardiovascular Assessment Study). Circulation 137(4):323-334. https://doi.org/ 10.1161/CIRCULATIONAHA.117.032038

30. Neal B, Perkovic V, Mahaffey KW et al (2017) Canagliflozin and cardiovascular and renal events in type 2 diabetes. N Engl J Med 377(7):644-657. https://doi.org/10.1056/NEJMoa1611925

31. Kosiborod M, Cavender MA, Fu AZ et al (2017) Lower risk of heart failure and death in patients initiated on sodium-glucose cotransporter-2 inhibitors versus other glucose-lowering drugs: the CVD-REAL study (comparative effectiveness of cardiovascular outcomes in new users of sodium-glucose cotransporter-2 inhibitors). Circulation 136:249-259

32. Wiviott SD, Raz I, Bonaca MP et al (2018) Dapagliflozin and cardiovascular outcomes in type 2 diabetes. N Engl J Med 380(4):347-357. https://doi.org/10.1056/NEJMoa1812389

33. Pessoa TD, Campos LC, Carraro-Lacroix L, Girardi AC, Malnic G (2014) Functional role of glucose metabolism, osmotic stress, and sodium-glucose cotransporter isoform-mediated transport on $\mathrm{Na}^{+} /$ $\mathrm{H}^{+}$exchanger isoform 3 activity in the renal proximal tubule. $\mathrm{J} \mathrm{Am}$ Soc Nephrol 25(9):2028-2039. https://doi.org/10.1681/ASN. 2013060588

34. Packer M, Anker SD, Butler J, Filippatos G, Zannad F (2017) Effects of sodium-glucose cotransporter 2 inhibitors for the treatment of patients with heart failure: proposal of a novel mechanism of action. JAMA Cardiol 2(9):1025-1029. https://doi.org/10.1001/ jamacardio.2017.2275

35. Dormandy JA, Charbonnel B, Eckland DJ et al (2005) Secondary prevention of macrovascular events in patients with type 2 diabetes in the PROactive study (PROspective pioglitAzone Clinical Trial In macroVascular Events): a randomised controlled trial. Lancet 366(9493):1279-1289. https://doi.org/10.1016/S0140-6736(05) 67528-9

36. Home PD, Pocock SJ, Beck-Nielsen H et al (2009) Rosiglitazone evaluated for cardiovascular outcomes in oral agent combination therapy for type 2 diabetes (RECORD): a multicentre, randomised, open-label trial. Lancet 373(9681):2125-2135. https://doi.org/10. 1016/S0140-6736(09)60953-3

37. Scirica BM, Braunwald E, Raz I et al (2014) Heart failure, saxagliptin, and diabetes mellitus: observations from the SAVORTIMI 53 randomized trial. Circulation 130(18):1579-1588. https:// doi.org/10.1161/CIRCULATIONAHA.114.010389
38. Scirica BM, Bhatt DL, Braunwald E et al (2013) Saxagliptin and cardiovascular outcomes in patients with type 2 diabetes mellitus. $\mathrm{N}$ Engl J Med 369(14):1317-1326. https://doi.org/10.1056/ NEJMoa1307684

39. Zannad F, Cannon CP, Cushman WC et al (2015) Heart failure and mortality outcomes in patients with type 2 diabetes taking alogliptin versus placebo in EXAMINE: a multicentre, randomised, doubleblind trial. Lancet 385(9982):2067-2076. https://doi.org/10.1016/ S0140-6736(14)62225-X

40. White WB, Kupfer S, Zannad F et al (2016) Cardiovascular mortality in patients with type 2 diabetes and recent acute coronary syndromes from the EXAMINE trial. Diabetes Care 39(7):12671273. https://doi.org/10.2337/dc16-0303

41. Green JB, Bethel MA, Armstrong PW et al (2015) Effect of sitagliptin on cardiovascular outcomes in type 2 diabetes. N Engl J Med 373(3):232-242. https://doi.org/10.1056/NEJMoa1501352

42. Yu OH, Filion KB, Azoulay L, Patenaude V, Majdan A, Suissa S (2015) Incretin-based drugs and the risk of congestive heart failure. Diabetes Care 38(2):277-284. https://doi.org/10.2337/dc14-1459

43. Giorda CB, Picariello R, Tartaglino B et al (2015) Hospitalisation for heart failure and mortality associated with dipeptidyl peptidase 4 (DPP-4) inhibitor use in an unselected population of subjects with type 2 diabetes: a nested case-control study. BMJ Open 5(6): e007959. https://doi.org/10.1136/bmjopen-2015-007959

44. Rosenstock J, Perkovic V, Johansen OE et al (2019) Effect of linagliptin vs placebo on major cardiovascular events in adults with type 2 diabetes and high cardiovascular and renal risk: the CARMELINA randomized clinical trial. JAMA 321(1):69-79. https://doi.org/10.1001/jama.2018.18269

45. Masoudi FA, Inzucchi SE, Wang Y, Havranek EP, Foody JM, Krumholz HM (2005) Thiazolidinediones, metformin, and outcomes in older patients with diabetes and heart failure: an observational study. Circulation 111(5):583-590. https://doi.org/10.1161/ 01.CIR.0000154542.13412.B1

46. Crowley MJ, Diamantidis CJ, McDuffie JR et al (2017) Clinical outcomes of metformin use in populations with chronic kidney disease, congestive heart failure, or chronic liver disease: a systematic review. Ann Intern Med 166(3):191-200. https://doi.org/10. 7326/M16-1901

47. Giamouzis G, Triposkiadis F, Butler J (2010) Metformin use in patients with diabetes mellitus and heart failure: friend or foe? J Card Fail 16(3):207-210. https://doi.org/10.1016/j.cardfail.2009. 12.007

48. Connelly KA, Gilbert RE, Liu P (2018) Treatment of diabetes in people with heart failure. Can J Diabetes 42(Suppl 1):s196-s200. https://doi.org/10.1016/j.jcjd.2017.10.026

49. Seferovic PM, Petrie MC, Filippatos GS et al (2018) Type 2 diabetes mellitus and heart failure: a position statement from the Heart Failure Association of the European Society of Cardiology. Eur J Heart Fail 20(5):853-872. https://doi.org/10.1002/ejhf.1170

50. Davies MJ, D’Alessio DA, Fradkin J et al (2018) Management of hyperglycaemia in type 2 diabetes, 2018. A consensus report by the American Diabetes Association (ADA) and the European Association for the Study of Diabetes (EASD). Diabetologia 61(12):2461-2498. https://doi.org/10.1007/s00125-018-4729-5

51. Margulies KB, Hernandez AF, Redfield MM et al (2016) Effects of liraglutide on clinical stability among patients with advanced heart failure and reduced ejection fraction: a randomized clinical trial. JAMA 316(5):500-508. https://doi.org/10.1001/jama.2016.10260

52. Jorsal A, Kistorp C, Holmager P et al (2017) Effect of liraglutide, a glucagon-like peptide-1 analogue, on left ventricular function in stable chronic heart failure patients with and without diabetes (LIVE)-a multicentre, double-blind, randomised, placebocontrolled trial. Eur J Heart Fail 19(1):69-77. https://doi.org/10. 1002/ejhf.657 
53. White WB, Cannon CP, Heller SR et al (2013) Alogliptin after acute coronary syndrome in patients with type 2 diabetes. N Engl J Med 369(14):1327-1335. https://doi.org/10.1056/NEJMoa1305889

54. Raschi E, Poluzzi E, Koci A, Antonazzo IC, Marchesini G, De Ponti F (2016) Dipeptidyl peptidase-4 inhibitors and heart failure: analysis of spontaneous reports submitted to the FDA adverse event reporting system. Nutr Metab Cardiovasc Dis 26(5):380-386. https://doi.org/10.1016/j.numecd.2016.02.006

55. McMurray JJV, Ponikowski P, Bolli GB et al (2018) Effects of vildagliptin on ventricular function in patients with type 2 diabetes mellitus and heart failure: a randomized placebo-controlled trial. JACC Heart Fail 6(1):8-17. https://doi.org/10.1016/j.jchf.2017. 08.004

56. Smooke S, Horwich TB, Fonarow GC (2005) Insulin-treated diabetes is associated with a marked increase in mortality in patients with advanced heart failure. Am Heart J 149(1):168-174. https:// doi.org/10.1016/j.ahj.2004.07.005

57. Shekelle PG, Rich MW, Morton SC et al (2003) Efficacy of angiotensin-converting enzyme inhibitors and beta-blockers in the management of left ventricular systolic dysfunction according to race, gender, and diabetic status: a meta-analysis of major clinical trials. J Am Coll Cardiol 41(9):1529-1538. https://doi.org/10.1016/ S0735-1097(03)00262-6

58. Carr AA, Kowey PR, Devereux RB et al (2005) Hospitalizations for new heart failure among subjects with diabetes mellitus in the RENAAL and LIFE studies. Am J Cardiol 96(11):1530-1536. https://doi.org/10.1016/j.amjcard.2005.07.061

59. Dei Cas A, Fonarow GC, Gheorghiade M, Butler J (2015) Concomitant diabetes mellitus and heart failure. Curr Probl Cardiol 40(1):7-43. https://doi.org/10.1016/j.cpcardiol.2014.09. 002

60. Phillips RA, Fonseca V, Katholi RE et al (2008) Demographic analyses of the effects of carvedilol vs metoprolol on glycemic control and insulin sensitivity in patients with type 2 diabetes and hypertension in the glycemic effects in diabetes mellitus: carvedilol-metoprolol comparison in hypertensives (GEMINI) study. J Cardiometab Syndr 3(4):211-217. https://doi.org/10.1111/ j.1559-4572.2008.00017.x
61. Pitt B, Zannad F, Remme WJ et al (1999) The effect of spironolactone on morbidity and mortality in patients with severe heart failure. Randomized Aldactone evaluation study investigators. N Engl J Med 341(10):709-717. https://doi.org/10.1056/ NEJM199909023411001

62. Zannad F, McMurray JJ, Krum H et al (2011) Eplerenone in patients with systolic heart failure and mild symptoms. N Engl J Med 364(1):11-21. https://doi.org/10.1056/NEJMoa1009492

63. Korol S, White M, O Meara E et al (2018) A comparison of the effects of selective and non-selective mineralocorticoid antagonism on glucose homeostasis of heart failure patients with glucose intolerance or type II diabetes: a randomized controlled double-blind trial. Am Heart J 204:190-195. https://doi.org/10.1016/j.ahj.2018. 07.002

64. McMurray JJ, Packer M, Desai AS et al (2014) Angiotensinneprilysin inhibition versus enalapril in heart failure. N Engl $\mathrm{J}$ Med 371(11):993-1004. https://doi.org/10.1056/NEJMoa1409077

65. Seferovic JP, Claggett B, Seidelmann SB et al (2017) Effect of sacubitril/valsartan versus enalapril on glycaemic control in patients with heart failure and diabetes: a post-hoc analysis from the PARADIGM-HF trial. Lancet Diabetes Endocrinol 5(5):333-340. https://doi.org/10.1016/S2213-8587(17)30087-6

66. Neal B, Perkovic V, de Zeeuw D et al (2013) Rationale, design, and baseline characteristics of the Canagliflozin cardiovascular assessment study (CANVAS) - a randomized placebo-controlled trial. Am Heart J 166(2):217-223.e11. https://doi.org/10.1016/j.ahj. 2013.05.007

67. Neal B, Perkovic V, Matthews DR et al (2017) Rationale, design and baseline characteristics of the Canagliflozin cardiovascular assessment study-renal (CANVAS-R): a randomized, placebocontrolled trial. Diabetes Obes Metab 19(3):387-393. https://doi. org/10.1111/dom.12829

Publisher's note Springer Nature remains neutral with regard to jurisdictional claims in published maps and institutional affiliations. 